Prosiding Seminar Nasional Teknologi Informasi dan Kedirgantaraan : Transformasi Teknologi untuk Mendukung Ketahanan Nasional, Yogyakarta, 13 Desember 2018

SENATIK 2018, Vol. IV, ISBN 978-602-52742-0-6

DOI: http://dx.doi.org/10.28989/senatik.v4i0.254

\title{
ANALYSIS ENGINE PERFORMANCE PT6A-114A AFTER APPLYING TBO EXTENSION WITH THE MANUFACTURE LIMITATION
}

\author{
Fajar Khanif Rahmawati \\ Program Studi Teknik Penerbangan \\ Sekolah Tinggi Teknologi Adisutjipto \\ Jl. Janti, Blok R, Lanud Adisutjipto Yogyakarta \\ Email : fajar.khanif@gmail.com
}

Abstract

Engine PT6A-114A is used on Cessna Grand Caravan 208B which has basic TBO: 3.600FH. Through condition monitoring, manufacturer issued SB1703R9 regarding the allowing extension TBO with terms and conditions. The analysis was done by comparing the condition of the TBO engine: 3.600FH and the engine that had been extended to TBO : $5.600 F H$. From the data by engine with TBO : 3.600FH and TBO : 5.600FH on the cruising phase, the ITT at each altitude does not exceed the maximum limitation which is $740^{\circ} \mathrm{C}$. Whereas the analytic calculations of the parameters in engine performances are: fuel / air ratio, thrust specifications, specific fuel consumption, thermal efficiency, propulsive efficiency, overall efficiency, and specific power, and it matches to the ideal conditions when compared to altitude. It can be concluded that parameters engine with TBO: $3.600 F H$ or $T B O$ : 5.600FH are still within the limits and engine parameters confirmed to ideal conditions.

Keyword: engine, overhoul, TBO extension, limitation, engine performance.

\section{Pendahuluan}

Indonesia sebagai negara kepulauan adalah salah satu negara yang sangat mengandalkan moda transportasi udara untuk mendukung sarana transpotasi dari satu pulau ke pulau lain. Banyak daerah yang masih sulit dijangkau dengan moda transportasi darat ataupun laut, sekalipun dapat dijangkau dengan transportasi darat, maka akan memerlukan waktu yang relatif lama dan medan yang tebilang cukup sulit. Maka transportasi udara merupakan pilihan utama yang akan mendukung sarana transportasi untuk menjangkau daerah-daerah tersebut. Misi penerbangan perintis adalah misi yang kemudian dikembangkan untuk dapat menjangkau daerah - daerah terpencil, baik untuk angkutan penumpang ataupun pendistribusian logistik.

Misi penerbangan perintis yang menjangkau daerah - daerah terpencil harus didukung dengan armada yang capabilty nya mampu untuk menjangkau daerah tersebut. Capability ini adalah terkait dengan kemampuan bandar udara di daerah tersebut yang umumnya tidak memiliki runway yang panjang dan bahkan masih berupa rumput (grass runway). Maka untuk tetap dapat menjalankan misi penerbangan perintis harus didukung dengan armada yang sesuai. Pesawat Cessna Grand Caravan 208B adalah salah satu pesawat yang banyak digunakan dalam penerbangan perintis.

Indonesia termasuk salah satu negara yang banyak mengoperasikan pesawat jenis Cessna Grand Caravan 208B terutama untuk misi penerbangan perintis. Penerbangan perintis umumnya akan menjangkau daerah - daerah pelosok yang memiliki medan yang sulit. Pemakaian jam terbang yang tinggi serta medan penerbangan harus menjadi perhatian yang khusus bagi setiap operator dalam pengoperasian ataupun perawatan armadanya. Demikian hal nya dengan pesawat Cessna Grand Caravan 208B ini, operator harus selalu memperhatikan upaya untuk menjaga armadanya tetap laik dan serviceable. Upaya ini salah 
satunya adalah dengan memperhatikan setiap notifikasi ataupun instruksi yang diberikan oleh manufaktur.

Engine PT6A-114A sebagai engine yang digunakan pada pesawat Cessna Grand Caravan 208B, harus mampu mendukung performa pesawat dalam menjalankan misinya. Sebagai salah satu major komponen pada pesawat engine PT6A-114A memiliki basic TBO: 3600FH. Perawatan overhoul yang dijadwalkan merupakan upaya perawatan preventive untuk mencegah terjadinya kegagalan. Dengan pelaksanaan overhoul diharapkan dapat membuat kodisi engine memiliki performa yang tetap baik.

Pratt and Whitney Canada selaku manufaktur dari engine PT6A-114A, mengeluarkan

Service Bulletin 1703R9, yang merupakan instruksi mengenai major inspection yaitu HSI ( Hot Section Inspection) dan TBO ( Time Between Overhoul) dari engine PT6A-114A yang merupakan engine dari pesawat Cessna Grand Caravan 208B [9]. Service Bulletin ini berisi instruksi dan aturan terkait diperbolehkannya memperpanjang usia overhoul engine dari ketentuan awal yaitu 3600FH. Mengingat overhoul merupakan salah satu major maintenance, yang hasilnya sangat mempengaruhi performa dari engine tersebut, maka dengan adanya perpanjangan overhoul akan memberi dampak pada performa engine. Sehingga operator harus memperhatikan beberapa konsekuensi jika akan menerapkan $T B O$ Extension ini. Dengan adanya perubahan yang disarankan oleh manufaktur ini, maka peneliti bermaksud untuk mengkaji performa dari engine yang telah mengalami perubahan TBO ( Time Between Overhoul ) terhadap limitasi yang ditentukan oleh manufaktur. Analisa hasil pengolahan data juga dilakukan untuk mengkaji penerapan kebijakan perawatan pada pesawat terbang terhadap performa dari komponen tersebut.

\section{Metodologi Penelitian}

Penelitian ini menggunakan metode kuantitatif. Metode kuantitatif yang digunakan dalam penelitian ini merupakan proses menemukan pengetahuan dengan menggunakan data berupa angka sebagai alat untuk menganalisis keterangan mengenai apa yang ingin diketahui [6]. Adapun data yang diperlukan dalam pengolahan data pada penelitian ini merupakan data parameter penerbangan yang diambil dari satu sampel engine PT6A-114A yang dioperasikan oleh PT. ASI Pudjiastuti Aviation yang telah diambil oleh peneleti [1]. Data tersebut diperoleh melalui Aircraft Flight Log yang merupakan catatan pilot selama penerbangan dilakukan. Data yang peneliti gunakan dalam penelitian ini sebagaimana tercantum pada table 1 dan tabel 2.

Data yang sudah peneliti peroleh berupa data altitude, OAT, ITT, dan IAS kemudian dianalisa dengan membandingkan kondisi real terhadap limitasi yang sudah ditentukan oleh manufaktur. Selain itu data juga diolah menggunakan pendekatan analitik dengan didukung konstanta engine turboprop yang merupakan jenis dari engine PT6A-114A [4] [5]. Melalui perhitungan diperoleh parameter-parameter untuk mengetahui performa dari engine tersebut.

Tabel 1 Data Engine dengan TBO 3600FH

\begin{tabular}{|c|c|c|c|c|c|}
\hline Altitude & \multicolumn{2}{|c|}{ OAT $\left(\mathbf{T}_{\mathbf{0}}\right)$} & \multicolumn{2}{|c|}{ ITT $\mathbf{( T t}_{\mathbf{4}} \mathbf{)}$} & IAS \\
\hline $\mathrm{ft}$ & ${ }^{\circ} \mathrm{C}$ & ${ }^{\circ} \mathrm{R}$ & ${ }^{\circ} \mathrm{C}$ & ${ }^{\circ} \mathrm{R}$ & Knot \\
\hline 4500 & 18 & 524,07 & 660 & 1679,67 & 146 \\
\hline 5500 & 20 & 527,67 & 675 & 1706,67 & 144 \\
\hline 6500 & 18 & 524,07 & 680 & 1715,67 & 141 \\
\hline 7500 & 16 & 520,47 & 680 & 1715,67 & 140 \\
\hline 8500 & 13 & 515,07 & 680 & 1715,67 & 137 \\
\hline 9500 & 12 & 513,07 & 680 & 1715,67 & 135 \\
\hline
\end{tabular}


Tabel 1 Lanjutan

\begin{tabular}{|c|r|c|c|c|c|}
\hline Altitude & \multicolumn{2}{|c|}{ OAT $\left(\mathbf{T}_{\mathbf{0}}\right)$} & \multicolumn{2}{|c|}{ ITT $\left(\mathbf{T t}_{\mathbf{4}}\right)$} & IAS \\
\hline $\mathrm{ft}$ & ${ }^{\circ} \mathrm{C}$ & ${ }^{\circ} \mathrm{R}$ & ${ }^{\circ} \mathrm{C}$ & $\mathrm{ft}$ & ${ }^{\circ} \mathrm{C}$ \\
\hline 10500 & 12 & 513,07 & 690 & 1733,67 & 132 \\
\hline 11500 & 9 & 507,87 & 690 & 1733,67 & 125 \\
\hline 12500 & 3 & 497,07 & 700 & 1751,67 & 125 \\
\hline 13500 & 3 & 497,07 & 700 & 1751,67 & 125 \\
\hline
\end{tabular}

Tabel 2 Data Engine dengan TBO 5600FH

\begin{tabular}{|c|r|c|c|c|r|}
\hline Altitude & \multicolumn{2}{|c|}{ OAT $\left(\mathbf{T}_{\mathbf{0}} \mathbf{)}\right.$} & \multicolumn{2}{|c|}{ ITT $\left(\mathbf{T t}_{\mathbf{4}} \mathbf{)}\right.$} & IAS \\
\hline $\mathrm{ft}$ & ${ }^{\circ} \mathrm{C}$ & ${ }^{\circ} \mathrm{R}$ & ${ }^{\circ} \mathrm{C}$ & ${ }^{0} \mathrm{R}$ & Knot \\
\hline 4500 & 20 & 527,67 & 690 & 1733,67 & 147 \\
\hline 5500 & 17 & 522,27 & 685 & 1724,67 & 140 \\
\hline 6500 & 15 & 518,67 & 685 & 1724,67 & 141 \\
\hline 7500 & 15 & 518,67 & 690 & 1733,67 & 138 \\
\hline 8500 & 14 & 516,87 & 695 & 1742,67 & 135 \\
\hline 9500 & 13 & 515,07 & 696 & 1744,47 & 132 \\
\hline 10500 & 12 & 513,27 & 695 & 1742,67 & 130 \\
\hline 11500 & 8 & 506,07 & 690 & 1733.67 & 132 \\
\hline 12500 & 7 & 504,27 & 692 & 1737,27 & 127 \\
\hline 13500 & 6 & 502,47 & 690 & 1733,67 & 125 \\
\hline
\end{tabular}

\section{Hasil dan Pembahasan}

Overhoul merupakan salah satu major maintenance yang masuk dalam kategori hard time maintenance karena batas waktu pelaksanaan overhoul telah ditentukan [7]. Akan tetapi dengan adanya kebijakan condition monitoring, yang mana dalam kasus engine PT6A-114A ini diterapkan melalui engine trend monitoring dapat mempengaruhi batas waktu hard time maintenance. Pemantauan kondisi engine oleh manufaktur melalui Engine Trend Monitoring, serta melalui evaluasi setiap pelaksanaan overhoul engine, maka manufaktur mengeluarkan kebijakan untuk memperpanjang usia overhoul engine sesuai syarat dan ketentuan yang sudah diatur dalam Service Bulletin 1703R9.

Engine PT6A-114A dengan serial number PC-1109 merupakan salah satu sampel engine yang pernah melaksanakan overhoul pada TBO : 3.600FH dan TBO : $5.600 \mathrm{FH}$. Artinya perpanjangan usia overhoul pada engine PT6A-114A yang dioperasikan PT. ASI Pudjiastuti telah dilakukan beberapa kali. Maka pada engine PT6A-114A dengan SN: PC-1109 ini dilakukan pengambilan data dari catatan pilot saat melakukan penerbangan cruising yang ditulis pada Aircraft Flight Log. Data yang digunakan dalam penelitian ini adalah dengan ketinggian mulai dari $4.500 \mathrm{ft}$ s/d $13.500 \mathrm{ft}$. Akan tetapi validasi data hanya sampai pada ketinggian $10.500 \mathrm{ft}$, dikarenakan kemampuan terbang cruising dari jenis pesawat ini hanya sampai pada $10.000 \mathrm{ft}$ [3].

Melalui data yang telah diperoleh, salah satu data yang dapat dianalisa terhadap limitasi dari manufaktur adalah data ITT pada setiap ketinggian pada engine dengan TBO : 3.600FH dan engine dengan TBO : 5.600FH. Adapun limitasi yang telah ditentukan oleh manufaktur sebagaimana terdapat pada tabel 3 [8]. 


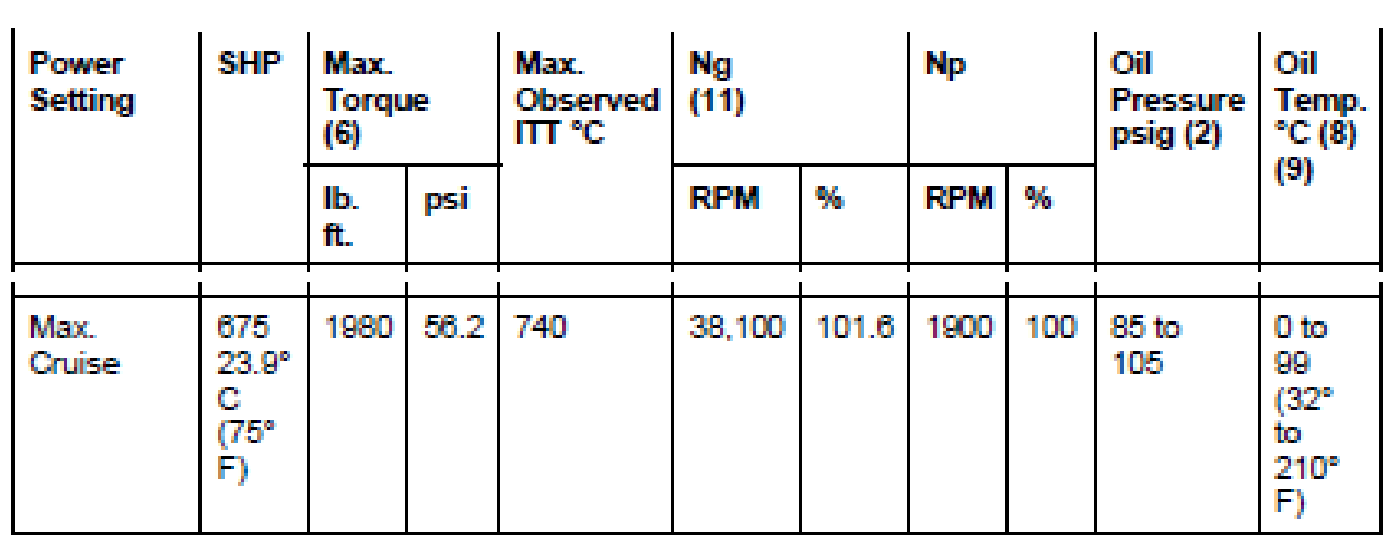

Tabel 3 Engine PT6A-114A Parameter

(Sumber. Engine Maintenance Manual PT6A-114A)

Berdasarkan data yang diperoleh pada fase terbang cruising, engine dengan TBO : 3.600FH dan TBO : 5.600FH, tidak melewati batas maksimal ITT yang telah ditentukan manufaktur yaitu $740^{\circ} \mathrm{C}$. Dengan demikian, meskipun usia overhoul engine telah diperpanjang dari 3.600FH menjadi 5.600FH tidak menurunkan kemampuan engine yang dalam hal ini adalah kondisi turbine temperatur yang kemudian menghasilkan power bagi engine untuk mendorong pesawat.

Selain membandingkan dengan limitasi yang telah ditentukan oleh manufaktur, performa dari engine yang telah melaksanakan overhoul pada TBO : $3.600 \mathrm{FH}$ dan TBO : 5.600FH juga dilakukan untuk mengetahui kondisi performa engine tersebut. Analisa dilakukan dengan metode analitik melalui perhitungan manual dengan rangkuman hasil perhitungan pada tabel 4 dan tabel 5 .

Tabel 4 Hasil Perhitungan Engine Performance dengan TBO : 3.600FH

\begin{tabular}{|c|c|c|c|c|c|c|c|}
\hline \multirow{2}{*}{$\boldsymbol{A l t}$} & \multicolumn{7}{|c|}{ Parameter } \\
\cline { 2 - 8 } & $\boldsymbol{F}$ & $\boldsymbol{F} / \mathbf{m O}$ & $\boldsymbol{S}$ & $\boldsymbol{\eta} \boldsymbol{\eta}$ & $\boldsymbol{\eta P}$ & $\boldsymbol{\eta} \boldsymbol{O}$ & $\boldsymbol{W} / \boldsymbol{m O}$ \\
\hline Ft & - & $l \mathrm{bf} /(\mathrm{lbm} / \mathrm{sec})$ & $(\mathrm{lbm} / \mathrm{hr}) / \mathrm{lbf}$ & $(\%)$ & $(\%)$ & $(\%)$ & $\mathrm{hp} /(\mathrm{lbm} / \mathrm{sec})$ \\
\hline $\mathbf{4 5 0 0}$ & 0,01282 & 179,34758 & 0,2574 & $15,5 \%$ & $45,6 \%$ & $7,1 \%$ & 36,61746 \\
\hline $\mathbf{5 5 0 0}$ & 0,01316 & 187,46922 & 0,25265 & $15,9 \%$ & $46,3 \%$ & $7,4 \%$ & 38,43129 \\
\hline $\mathbf{6 5 0 0}$ & 0,01339 & 194,73638 & 0,24754 & $16,1 \%$ & $46,8 \%$ & $7,5 \%$ & 39,78097 \\
\hline $\mathbf{7 5 0 0}$ & 0,01348 & 195,958 & 0,2476 & $16,3 \%$ & $47,2 \%$ & $7,7 \%$ & 40,438 \\
\hline $\mathbf{8 5 0 0}$ & 0,01361 & 201,577 & 0,24314 & $16,5 \%$ & $47,7 \%$ & $7,9 \%$ & 41,401 \\
\hline $\mathbf{9 5 0 0}$ & 0,01366 & 202,938 & 0,24239 & $16,6 \%$ & $47,8 \%$ & $7,9 \%$ & 41,763 \\
\hline $\mathbf{1 0 5 0 0}$ & 0,01395 & 211,072 & 0,23792 & $16,8 \%$ & $48,3 \%$ & $8,1 \%$ & 43,173 \\
\hline $\mathbf{1 1 5 0 0}$ & 0,01409 & 223,81 & 0,22666 & $17,0 \%$ & $48,6 \%$ & $8,3 \%$ & 44,055 \\
\hline $\mathbf{1 2 5 0 0}$ & 0,014642 & 237,176 & 0,22225 & $17,6 \%$ & $49,9 \%$ & $8,8 \%$ & 47,433 \\
\hline $\mathbf{1 3 5 0 0}$ & 0,01464 & 233,615 & 0,22556 & $17,6 \%$ & $49,9 \%$ & $8,8 \%$ & 47,456 \\
\hline
\end{tabular}


Tabel 5 Hasil Perhitungan Engine Performance dengan TBO : 5.600FH

\begin{tabular}{|c|c|c|c|c|c|c|c|}
\hline \multirow{2}{*}{$\boldsymbol{A l t}$} & \multicolumn{7}{|c|}{ Parameter } \\
\cline { 2 - 8 } & $\boldsymbol{F}$ & $\boldsymbol{F} / \boldsymbol{m O}$ & $\boldsymbol{S}$ & $\boldsymbol{\eta} \boldsymbol{\eta}$ & $\boldsymbol{\eta P}$ & $\boldsymbol{\eta} \boldsymbol{O}$ & $\boldsymbol{W} / \mathbf{m O}$ \\
\hline$F t$ & - & $l \mathrm{bf} /(\mathrm{lbm} / \mathrm{sec})$ & $(\mathrm{lbm} / \mathrm{hr}) / \mathrm{lbf}$ & $(\%)$ & $(\%)$ & $(\%)$ & $\mathrm{hp} /(\mathrm{lbm} / \mathrm{sec})$ \\
\hline $\mathbf{4 5 0 0}$ & 0,01358 & 197,30221 & 0,24781 & $16,1 \%$ & $46,8 \%$ & $7,5 \%$ & 40,55917 \\
\hline $\mathbf{5 5 0 0}$ & 0,01358 & 204,62589 & 0,23899 & $16,3 \%$ & $47,2 \%$ & $7,7 \%$ & 40,78318 \\
\hline $\mathbf{6 5 0 0}$ & 0,01367 & 202,94439 & 0,24245 & $16,5 \%$ & $47,6 \%$ & $7,9 \%$ & 41,45771 \\
\hline $\mathbf{7 5 0 0}$ & 0,01381 & 207,27105 & 0,23987 & $16,6 \%$ & $47,8 \%$ & $7,9 \%$ & 42,16113 \\
\hline $\mathbf{8 5 0 0}$ & 0,014 & 213,381 & 0,23619 & $16,8 \%$ & $48,1 \%$ & $8,1 \%$ & 43,18632 \\
\hline $\mathbf{9 5 0 0}$ & 0,01408 & 216,9764 & 0,23358 & $16,9 \%$ & $48,3 \%$ & $8,2 \%$ & 43,65917 \\
\hline $\mathbf{1 0 5 0 0}$ & 0,014123 & 218,34377 & 0,23285 & $16,9 \%$ & $48,5 \%$ & $8,2 \%$ & 43,98358 \\
\hline $\mathbf{1 1 5 0 0}$ & 0,01412 & 213,84414 & 0,23771 & $17,1 \%$ & $48,9 \%$ & $8,4 \%$ & 44,45087 \\
\hline $\mathbf{1 2 5 0 0}$ & 0,014173 & 220,20857 & 0,23169 & $17,2 \%$ & $49,0 \%$ & $8,4 \%$ & 44,74437 \\
\hline $\mathbf{1 3 5 0 0}$ & 0,014211 & 221,69895 & 0,23077 & $17,2 \%$ & $49,1 \%$ & $8,4 \%$ & 45,0358 \\
\hline
\end{tabular}

Dari hasil yang telah di dapatkan maka dapat dijelaskan bahwa:

Perbandingan Parameter Fuel/Air Ratio terhadap Altitude

Fuel/Air Ratio adalah rasio perbandingan antara fuel dan udara yang didasarkan pada setiap perbedaan altitude. Pada umumnya dalam setiap pertambahan ketinggian rasio fuel yang digunakan akan semakin sedikit, begitupun dengan kerapatan udara pada setiap pertambahan ketinggian juga akan mengalami penurunan, akan tetapi besar penurunan fuel tidak sebesar penurunan kerapatan udara sehingga menyebabkan nilai dari fuel air ratio pada setiap pertambahan ketinggian cenderung meningkat.

Dari perbandingan parameter Fuel/Air Ratio terhadap Altitude diatas dapat diketahui bahwa nilai fuel/air ratio akan mengalami kenaikan setiap pertambahan ketinggian. Dari tabel 4 dan tabel 5 terlihat bahwa perbandingan nilai fuel/air ratio pada ketinggian antara engine TBO $: 3.600 \mathrm{FH}$ dan TBO $: 5.600 \mathrm{FH}$ terdapat perbedaan nilai yang cukup significant, dimana pada engine yang dilakukan TBO : 5.600FH secara keseluruhan nilainya jauh lebih tinggi dibandingkan dengan engine yang dilakukan $T B O: 3.600 \mathrm{FH}$. Hal ini dapat dikatakan bahwa engine dengan TBO : 5.600FH rasio penggunaan fuel-nya jauh lebih tinggi dibandingkan dengan engine dengan TBO : 3.600FH.

Namun seiring dengan pertambahan ketinggian nilai perbandingan antara fuel dan air menjadi semakin besar, hal ini dikarenakan rasio penurunan air atau kerapatan udara jauh lebih cepat atau dapat dikatakan jauh lebih tinggi dibandingkan dengan penurunan fuel consumption, hal inilah yang mengakibatkan setiap kenaikan ketinggian penerbangan fuel/air ratio-nya akan mengalami peningkatan.

\section{Perbandingan Parameter Specific Thrust}

Specific Thrust merupakan perbandingan antara thrust yang dihasilkan oleh pesawat dan masa aliran udara pada setiap ketinggian. Seperti halnya pada fuel/air ratio, specific thrust juga akan mengalami peningkatan pada setiap pertambahan ketinggian.

Dari perbandingan parameter specific thrust terhadap altitude pada tabel 4 dan tabel 5 dapat diketahui bahwa nilai specific thrust akan semakin meningkat setiap pertambahan ketinggian, hal ini disebabkan karena setiap kenaikan ketinggan maka density atau kerapatan udaranya akan semakin berkurang sehingga mengakibatkan penurunan temperatur udara, dari penurunan temperatur udara inilah yang nantinya akan mengakibatkan kenaikan dari 
kompresi engine. Apabila kompresi dari engine ini meningkat maka nilai specific thrust akan semakin besar. Dari tabel 4 dan tabel 5 dapat diketahui bahwa nilai specific thrust mengalami peningkatan dari ketinggian $4.500 \mathrm{ft}$ s.d $10.500 \mathrm{ft}$, namun pada engine TBO : 5.600FH terjadi penurunan pada ketinggian $11.500 \mathrm{ft}$ hal ini dikarenakan data yang diambil berasal dari catatan pilot yang dituliskan dalam flight log. Mengacu pada spesifikasi pesawat yang merupakan cabin unpressurized, maka dalam fase cruising constant hanya dapat dilakukan pada maksimal ketinggian $10.000 \mathrm{ft}$, melebihi batas tersebut kestabilan fase cruising tidak dapat dilakukan. Maka besar kemungkinan terjadinya ketidakakuratan dalam melakukan record data yang tertulis pada flight log. Selain itu dapat diketahui juga bahwa besar kecilnya specific thrust juga dipengaruhi oleh fuel/air ratio dimana semakin besar fuel yang digunakan maka specific thrust-nya akan semakin meningkat.

\section{Perbandingan Parameter Specific Fuel Consumption (S)}

Specific fuel consumption atau yang lebih sering dikenal dengan istilah konsumsi bahan bakar spesifik engine, yaitu merupakan nilai yang diperoleh dari perbandingan antara fuel/air ratio dengan specific thrust engine. Pada setiap perbedaan ketinggian, nilai dari specific fuel consumption akan mengalami perbedaan, hal ini di pengaruhi oleh adanya perbedaan dari fuel/air ratio dengan specific thrust.

Berdasarkan tabel tentang perbandingan parameter specific fuel consumption diatas, dapat diketahui bahwa seiring dengan pertambahan ketinggian nilai specific fuel consumption akan mengalami penurunan. Pada tabel diatas terdapat perbedaan antara engine dengan TBO : $3.600 \mathrm{FH}$ dan engine dengan $\mathrm{TBO}: 5.600 \mathrm{FH}$, dimana secara keseluruhan engine dengan TBO : 3.600FH jauh lebih tinggi dibandingkan dengan engine TBO : $5.600 \mathrm{FH}$. Specific fuel consumption pada engine TBO : 5.600 hours mengalami penurunan pada ketinggian $4.500 \mathrm{ft}$ s.d. $10.500 \mathrm{ft}$, namun pada ketinggian $11.500 \mathrm{ft}$ mengalami kenaikan yang mana tidak sesuai dengan teori pada umumnya. Apabila ditinjau dari nilai specific thrust yang di dapatkan sebelumnya, tidak menutup kemungkinan juga terjadi ketidak akuratan dalam perhitungan specific fuel consumption yang dimana fuel consumption merupakan rasio perbandingan dari fuel/air ratio dan specific thrust.

\section{Perbandingan Parameter Thermal Efficiency}

Thermal efficiency adalah suatu parameter yang mempuyai fungsi untuk mengetahui tingkat derajat panas dari suatu engine. Tingkat derajat panas dari suatu engine ini dipengaruhi oleh kerja dari engine itu sendiri. Apabila kerja suatu engine semakin berat maka nilai derajat panas dari engine tersebut juga akan semakin meningkat.

Dari tabel 4 dan tabel 5 tentang perbandingan parameter thermal efficiency dapat diketahui bahwa thermal efficiency akan semakin meningkat seiring dengan pertambahan ketinggian. Pada tabel 4 dan tabel 5 diketahui bahwa pada ketinggian $4.500 \mathrm{ft}$ s.d. $11.500 \mathrm{ft}$ thermal efficiency engine pada TBO : 3.600FH jauh lebih rendah dibandingkan dengan engine TBO : 5.600FH, namun pada ketinggian diatas $11.500 \mathrm{ft}$ engine dengan TBO : 3.600FH memiliki nilai thermal efficiency yang lebih tinggi dibandingkan engine TBO : $5.600 \mathrm{FH}$. Hal ini dipengaruhi karena adanya perbedaan temperature pada setiap perbedaan ketinggian.

Berdasarkan hasil yang di dapatkan maka dapat diketahui bahwa engine dengan TBO : 5.600FH lebih mudah panas dibandingan dengan engine TBO : 3.600FH. Faktor lain penyebab ini adalah dapat dipengaruhi oleh usia dari engine PT6A-114A dengan serial number PCE-PC1109 itu sendiri. 


\section{Perbandingan Parameter Propulsive Efficiency}

Propulsive Efficiency atau efisiensi propulsi adalah suatu parameter yang digunakan untuk mengetahui tingkat propulsi engine atau tingkat kinerja engine. Propulsi dari suatu engine merupakan hal yang utama yang harus diperhatikan, karena apabila terdapat gangguan pada sistem kerja engine maka akan berpengaruh pada thrust yang dikasilkan oleh engine tersebut.

Dari tabel 4 dan tabel 5 tentang perbandingan parameter propulsive efficiency dapat diketahui bahwa propulsive efficiency akan semakin meningkat seiring dengan pertambahan ketinggian. Pada tabel 4 dan 5 diketahui bahwa secara keseluruhan propulsive efficiency engine dengan TBO : 5.600FH lebih tinggi dibandingkan engine TBO : 3.600FH, dengan perbedaan pada setiap ketinggiannya tidak melebihi 1\%, sehingga dapat dikatakan bahwa engine TBO : 5.600FH gaya dorongnya jauh lebih besar dibandingkan dengan engine TBO $: 3.600 \mathrm{FH}$. Hal ini dapat terjadi mengingat adanya perbedaan treatment yang dilakukan pada kedua kondisi, dimana pada saat pelaksanaan overhaul, engine dengan TBO : 3.600FH tidak semua komponennya dilakukan penggantian melainkan hanya dilakukan repair, sedangkan pada engine dengan TBO : 5.600FH lebih banyak komponen yang telah habis life limitnya sehingga juga sekaligus dilakukan penggantian komponen tersebut.

\section{Perbandingan Parameter Overall Efficiency}

Overall Efficiency atau efisiensi keseluruhan, yaitu suatu parameter yang didapatkan dari perkalian antara thermal efficiency dan propulsive efficiency. Dari tabel 4 dan tabel 5 tentang perbandingan parameter overall efficiency dapat diketahui bahwa nilai overal efficiency akan mengalami kenaikan seiring dengan pertambahan ketinggian. Pada ketinggian $4.500 \mathrm{ft}$ s.d. $11.500 \mathrm{ft}$ overall efficiency engine dengan TBO : 5.600FH lebih tinggi dibandingkan dengan engine TBO : 3.600FH, sedangkan pada ketinggian diatas $11.500 \mathrm{ft}$ terjadi sebaliknya. Besar kecilnya nilai overall efficiency ini dipengaruhi oleh besar dari thermal efficiency dan propulsive efficiency yang di dapatkan pada perhitungan sebelumnya.

\section{Perbandingan Parameter Specific Power}

Spesific power adalah suatu parameter yang digunakan untuk mengetahui tingkat power spesifik dari suatu engine. Specific power ini didapatkan dari nilai power yang dihasilkan pada suatu engine berbanding dengan masa aliran udara yang mengalir. Dari tabel tentang perbandingan parameter specific power dapat diketahui bahwa pada umumnya nilai dari specific power akan semakin meningkat seiring dengan pertambahan ketinggian. Pada ketinggian $4.500 \mathrm{ft}$ s.d. $11.500 \mathrm{ft}$ engine dengan TBO : 5.600FH cenderung lebih tinggi dibandingkan dengan engine TBO : $3.600 \mathrm{FH}$, sehingga dapat dikatakan bahwa specific power engine TBO : 5.600FH lebih besar dibandingkan engine dengan TBO : 3.600FH. Mengingat bahwa ada perbedaan treatment yang dilakukan antara engine yang dilakukan overhoul pada TBO : 3.600FH dan TBO : 5.600FH, maka tidak menutup kemungkinan bahwa engine yang dioverhoul mempunyai nilai specific power yang lebih unggul dibandingan dengan pada saat overhoul TBO : 3.600FH.

Adapun treatment yang dilakukan antara lain perbedaan life limit dari accessories, dan penggantian LLP dimana pada saat TBO tidak semua LLP dilakukan penggantian sedangkan pada saat TBO extension (5.600 hours) semua LLP habis life limit-nya, sehingga dilakukan penggantian. Selain itu, juga dipengaruhi adanya kebijakan perusahaan dimana adanya perubahan pelaksanaan inspection yang dilakukan.

\section{Kesimpulan}

Dari pengolahan data yang telah dilakukan maka dapat disimpulkan bahwa : 
1. Parameter engine PT6A-114A yaitu ITT pada fase cruising masih dalam batas limitasi yang telah ditentukan oleh manufaktur yaitu $740^{\circ} \mathrm{C}$.

2. Pada engine PT6A-114A dengan TBO:3600FH dan TBO:5600FH memiliki parameter performa engine yaitu: fuel/air ratio, spesifc thrust, specific fuel consumption, thermal efficiency, propulsive efficiency, overall efficiency, dan specific power yang sesuai dengan kondisi ideal. Adapun perbedaan hasil pada engine TBO:3600FH dan TBO:5600FH adalah dikarenakan adanya perbedaan perlakuan pada masing - masing overhoul seperti adanya penggantian life limit part pada engine dengan TBO:5600FH.

\section{Ucapan terimakasih}

Ucapan terimakasih penulis sampaikan kepada P3M STT Adisutjipto yang telah berperan dalam memberikan bantuan dana dalam pelaksanaan penelitian ini.

\section{Daftar Pustaka}

[1] Anggraeni, Tanty., 2018, Analisis Specisific Power dan Spesific Fuel Consumption pada Engine PT6A-114A SN:PC-1109 Sebelum dan Sesudah Mengalami TBO Extension, STT Adisutjipto, Yogyakarta.

[2] Arismunandar, Wiranto. 2002, "Pengantar Turbin Gas dan Motor Propulsi", Penerbit ITB, Bandung.

[3] Cessna Technical Publication, 2013, "Cessna Grand Caravan 208B Pilot's Operating Hand Book and FAA Airplane Flight Manual Rev.01", USA.

[4] Jack D. Mattingly, 2002, “Aircraft Engine Design $2^{\text {nd }}$ Edition, American Institute of Aeronautics and Astronatics".

[5] Jack D. Mattingly, 2005 "Element of Gas Turbine Propulsion, Department of Mechanical and Manufacturing Engineering Seattle University”, USA.

[6] Kasiram, Moh, 2008, Metodologi Penelitian, Malang, UIN-Malang Pers.

[7] Kinnison A, Harry dan Siddiqui, T., 2004, Aviation Maintenance Manajemen 2nd Edition, The Mc Graw-Hill, New York.

[8] Pratt \& Whitney Technical Publication, 2018, Engine PT6A-114A Maintenance Manual.

[9] Pratt \& Whitney, 2013. "Pratt \& Whitney S.B. No. 1703R9 Turboprop Engine Operating Time Between Overhauls and Hot Section Inspection Frequency, Canada. 